\title{
SABERES POPULARES E EDUCAC̦ÃO CIENTÍFICA: UM OLHAR A PARTIR DA LITERATURA NA ÁREA DE ENSINO DE CIÊNCIAS
}

\author{
Patrícia Maria Azevedo Xavier* \\ Cristhiane Carneiro Cunha Flôr **
}

RESUMO: Apresentamos um olhar para a literatura na área de Educação Científica sobre o tema saberes populares, procurando compreender como este é tratado pela pesquisa em Ensino de Ciências. Realizamos uma revisão em seis periódicos nacionais da área de ensino/aprendizagem de ciências publicados entre 2000 e 2012 e, posteriormente, buscamos outras publicações dos autores levantados. Após a leitura dos trabalhos, construímos quatro categorias: Reflexões teóricas; Novas alternativas didáticas; Troca de conhecimentos com a comunidade; Investigação das transformações ocorridas ao longo do tempo. A pesquisa sobre a inserção de saberes populares no Ensino de Ciências ainda é incipiente e concentra-se no desenvolvimento de novas alternativas didáticas, o que mostra um movimento no sentido de aproximar, por meio da pesquisa, os saberes populares do conhecimento escolar.

Palavras-chave: Saberes populares. Ensino de Ciências. Revisão de literatura.

FOLK WISDOM AND SCIENCE EDUCATION: A REVIEW FROM THE NATIONAL LITERATURE

ABSTRACT: We present a Science Education literature review about folk wisdom, trying to understand how this subject is approached by research in science education. We did a revision in six Brazilian periodicals that published articles about science education/science learning, between 2000 and 2012 and, subsequently, sought other publications from the same authors. After reading the papers, we classified them in four categories: Theoretical reflections; New educational alternatives; Knowledge exchange with the community; Investigation of transformation over time. Research on folk wisdom's inclusion in science education is still incipient and focuses on the development of new teaching alternatives. This shows a movement in the sense to approximate, through the research, conventional knowledge to school knowledge.

Keywords: Folk wisdom. Science education. Literature review.

DOI - http://dx.doi.org/10.1590/1983-21172015170202 
SABERES POPULARES Y EDUCACIÓN CIENTÍFICA: UNA MIRADA A LA LITERATURA EN EL CAMPO DE ENSEÑANZA DE LAS CIENCIAS

RESUMEN: Presentamos una mirada a la literatura en el campo de la Educación Científica acerca del tema saberes populares, buscando comprender como es tratado por la investigación en la Enseñanza de las Ciencias. Realizamos una revisión en seis revistas científicas brasileñas de la área de enseñanza/aprendizaje de las ciencias publicadas entre 2000 y 2012 y, en seguida, buscamos otras publicaciones de los autores encontrados. Después de la lectura de los trabajos, construimos cuatro categorías: Reflexiones teóricas; Nuevas alternativas didácticas; Intercambio de conocimientos con la comunidad; Investigación de las transformaciones a lo largo del tiempo. La investigación acerca de la inserción de saberes populares en la Enseñanza de las Ciencias es aún incipiente y se concentra en el desarrollo de nuevas alternativas didácticas, lo que muestra un movimiento en el sentido de aproximar, por medio de la investigación, los saberes populares del conocimiento escolar.

Palabras clave: Saberes populares. Enseñanza de las Ciencias. Revisión de la literatura. 


\section{INTRODUCุÃO}

Vivemos em um país que, devido à sua própria história, apresenta uma diversidade enorme de crenças, culturas e formas de expressão, o que torna cada comunidade única, com características próprias. Acreditamos que essas especificidades precisam ser consideradas na prática educacional local que deve, portanto, valorizar e resgatar os saberes vindos da sociedade e que os estudantes trazem consigo, fruto de sua vivência. Assim, a escola deve ser "o local de mediação entre a teoria e a prática, o ideal e o real, o científico e o cotidiano" (GONDIM; MÓL, 2009, p. 2). Como um caminho que contempla essa necessidade do Ensino de Ciências, Chassot defende o resgate e a valorização de saberes populares, trazendo-os para as salas de aula. O diálogo entre os saberes escolares e populares seria, nesse contexto, mediado pelo conhecimento científico, compreendido como facilitador da leitura do mundo natural (CHASSOT, 2008a).

Os saberes populares, manifestados como chás medicinais, artesanatos, mandingas, culinária, entre outros, fazem parte da prática cultural de determinado local e grupo coletivo. São conhecimentos obtidos empiricamente, a partir do "fazer", que são transmitidos e validados de geração em geração, principalmente por meio da linguagem oral, de gestos e atitudes (GONDIM, 2007). Para Chassot (2006, p. 205), "os saberes populares são os muitos conhecimentos produzidos solidariamente e, às vezes, com muita empiria”. Para Pinheiro e Giordan (2010), embora algumas dessas práticas sejam realizadas sem um entendimento do porquê dos procedimentos, baseando-se em crenças e opiniões, outro grupo de saberes é constituído por explicações mais elaboradas, apropriando-se de outros conhecimentos. Dessa forma, consideramos os saberes populares como um conjunto de conhecimentos elaborados por pequenos grupos (famílias, comunidades), fundamentados em experiências ou em crenças e superstições, e transmitidos de um indivíduo para outro, principalmente por meio da linguagem oral e dos gestos. A partir de 2008, Chassot passou a nomear os saberes populares de saberes primevos, referindo-se a saberes dos primeiros tempos, inicial, primeiro. A substituição foi feita a fim de não desqualificar esses saberes, como pode ocorrer quando da utilização do adjetivo "popular" (CHASSOT, 2008b).

Os saberes populares são apontados como conhecimentos "à margem das instituições formais" (LOPES, 1999, p. 152). Na escola, a cultura dominante é transmitida como algo natural, sem ser questionada, e os saberes primevos dificilmente são valorizados, já que não são validados pela Academia. Alguns autores (CHASSOT, 2006; PINHEIRO; GIORDAN, 2010; GONDIM, 2007) têm assinalado como função da escola a valorização desse conhecimento. Não se trata de uma supervalorização do saber popular, mas sim reconhecer o conhecimento existente nas práticas cotidianas de uma parcela da população que, muitas vezes, não é vista como detentora de saber. Trata de desconstruir o paradigma de uma única forma de educação, baseada somente no conhecimento científico, e explorar novas possibilidades. 
Com base no exposto, buscamos com o presente estudo levantar trabalhos que abordam o tema "saberes populares", procurando compreender como é tratado pela pesquisa na área de Educação em Ciências no Brasil, e quais as interlocuções propostas entre esses saberes e o Ensino de Ciências, como parte de um projeto maior, de dissertação de mestrado. Apresentamos, a seguir, um panorama de pesquisas realizadas no Brasil que aliam o Ensino de Ciências aos saberes populares.

\section{METODOLOGIA}

Realizamos, inicialmente, um levantamento bibliográfico em quatro revistas nacionais que trazem publicações em ensino/aprendizagem de ciências (Ciência e Educação, Ensaio, Investigações em Ensino de Ciências e Revista Brasileira de Pesquisa em Educação em Ciências), além das revistas vinculadas à Sociedade Brasileira de Química (Química Nova e Química Nova na Escola), uma vez que a dissertação da qual o estudo apresentado faz parte tem como foco saberes populares articulados a conhecimentos químicos. Consultamos os volumes online publicados entre os anos 2000 e 2012. Embora as revistas não representem o todo das publicações na área de ensino/aprendizagem de ciências, elas representam diferentes instituições - tais como, UNESP, UFMG, UFRGS, USP, SBQ - e grupos que não só divulgam os trabalhos, mas também realizam pesquisas em educação científica. Além disso, são periódicos classificados no Qualis CAPES no extrato A-B na área de ensino. Acreditamos, portanto, que as revistas escolhidas nos fornecem um bom panorama das pesquisas realizadas na área no recorte temporal do estudo.

Para seleção dos trabalhos, buscamos, ano a ano, nos índices dos periódicos pelos títulos e palavras-chave que remetessem ao tema "saberes populares", sendo consultados um total de 1764 títulos. Partimos, então, para a leitura dos resumos e, posteriormente, para a íntegra dos trabalhos que se enquadravam no tema proposto. Como critério para seleção dos trabalhos, procuramos pelas seguintes palavras-chave: saber popular, saberes cotidianos e conhecimentos tradicionais além de termos que remetessem a práticas artesanais tradicionais, sendo encontradas, por exemplo, as palavras tecelagem manual, cachaça, sabão de cinzas etc. Entretanto, encontramos um número muito reduzido de trabalhos, apenas oito artigos tratando da busca e inserção de saberes populares no Ensino de Ciências (ALMEIDA, 2012; BAPTISTA, 2010; CHASSOT, 2008a; GONDIM; MÓL, 2008; RESENDE; CASTRO; PINHEIRO, 2010; PINHEIRO; GIORDAN, 2010; SILVA; AGUIAR; MEDEIROS, 2000; VENQUIARUTO et al., 2011). Desses artigos, cinco foram publicados na revista Química Nova na Escola, dois na revista Ciência e Educação e um na revista Investigações em Ensino de Ciências.

Para aprofundarmos nossa pesquisa, optamos por realizar buscas a partir dos autores levantados inicialmente, bem como das referências por eles utilizadas. Para tanto, consultamos os currículos desses autores, disponíveis na Plataforma 
Lattes, procurando outras publicações que estivessem disponíveis online. Nesse segundo movimento, encontramos mais trinta trabalhos, entre artigos em periódicos e publicações em congressos.

A fim de categorizarmos os trabalhos, construímos, para cada um, uma ficha na qual identificamos: o objeto de estudo, a metodologia de pesquisa utilizada e os objetivos. A partir desse movimento, foram elaboradas quatro categorias:

- Novas alternativas didáticas - estudos que têm como objetivo a proposição de alternativas didáticas de inserção dos saberes populares na sala de aula, com o desenvolvimento de materiais e sequências didáticas, experimentos, entre outros, que contemplam desde as séries iniciais do Ensino Fundamental até o ensino superior.

- Troca de conhecimentos com a comunidade: estudos que destacam a preocupação de alguns pesquisadores em fornecer um retorno para as comunidades pesquisadas, estudando e aprimorando as práticas investigadas.

- Investigando as transformações ocorridas ao longo do tempo: estudos que abordam a preocupação em perceber como esses saberes se modificam ao longo do tempo.

- Reflexões teóricas: estudos que apresentam uma discussão teórica em torno dos saberes populares e suas articulações com o Ensino de Ciências.

Os trabalhos que compõem cada categoria são mostrados no quadro abaixo:

Quadro 1 - Artigos selecionados por categoria

\begin{tabular}{|c|c|c|}
\hline Categoria & $\begin{array}{l}\text { Número de } \\
\text { trabalhos }\end{array}$ & Autores \\
\hline $\begin{array}{l}\text { Reflexões } \\
\text { Teóricas }\end{array}$ & 4 & $\begin{array}{l}\text { BAPTISTA (2010); LOPES (1993)' ; SILVA (2002); } \\
\text { SILVA (2004). }\end{array}$ \\
\hline $\begin{array}{c}\text { Novas } \\
\text { alternativas } \\
\text { didáticas }\end{array}$ & 26 & $\begin{array}{l}\text { ALMEIDA (2012); CALDEIRA E PINHEIRO (2010); } \\
\text { CHASSOT (2004, 2007, 2008A); GOMES E PINHEIRO } \\
\text { (2000A, 2000B); PINHEIRO (2012); PINHEIRO E } \\
\text { GIORDAN (2010); GONDIM E MÓL (2008A, 2008B); } \\
\text { MENEGAT E VENQUIARUTO (2006); PRIGOL E DEL } \\
\text { PINO (2008, 2009); PRIGOL E VENQUIARUTO (2006); } \\
\text { SANTOS ET AL. (2012); SIQUEIRA E CHASSOT } \\
\text { (2004); RESENDE, CASTRO E PINHEIRO (2010); } \\
\text { VENQUIARUTO, DALLAGO E DEL PINO (2012); } \\
\text { VENQUIARUTO ET AL. (2010, 2011A, 2011B, 2013A, } \\
\text { 2013B, 2013C); VENQUIARUTO, DALLAGO E } \\
\text { DACROCE (2009). }\end{array}$ \\
\hline
\end{tabular}




\begin{tabular}{|c|c|c|}
\hline $\begin{array}{c}\text { Troca de } \\
\text { conhecimentos } \\
\text { coma } \\
\text { comunidade }\end{array}$ & 3 & $\begin{array}{c}\text { CAMPOS (2007); SILVA, AGUIAR E MEDEIROS (2000); } \\
\text { STOCKMANN ET AL. (2007). }\end{array}$ \\
\hline $\begin{array}{c}\text { Investigação das } \\
\text { transformações } \\
\text { ocorridas ao } \\
\text { longo do tempo }\end{array}$ & 5 & $\begin{array}{c}\text { ALMEIDA (2008, 2011); GONDIM E MÓL (2009); } \\
\text { MENDES E ALMEIDA (2011); REICHERT (2000). }\end{array}$ \\
\hline
\end{tabular}

Fonte: Quadro elaborado pelas autoras deste artigo.

\section{REFLEXÕES TEÓRICAS}

Agrupamos nessa primeira categoria aqueles trabalhos que trouxeram contribuições teóricas sobre saberes populares e sua inserção no Ensino de Ciências. Ao escrever sobre a teoria do currículo e sobre a constituição social do conhecimento, Lopes (1993) trata, primeiramente, de distinguir senso comum e saber popular. Para essa autora, o senso comum apoia-se na experiência primeira, no aparente e nos fenômenos evidentes, constituindo, assim, um obstáculo ao conhecimento científico. A ciência seria construída a partir da ruptura com o senso comum, o que é um processo permanente e nunca completamente superado. $\mathrm{O}$ senso comum compreende, ainda, aqueles saberes que guiam os homens, independentemente de grupo ou classe social, possuindo, assim, um caráter transclassista. O saber popular, por outro lado, é produzido por grupos específicos, não permeando a sociedade como um todo. São conhecimentos que permitem ao grupo viver melhor, mas não têm a função de orientação, como o senso comum. O saber popular é, portanto, múltiplo, no sentido que é diferente para cada comunidade, "enquanto o senso comum aponta para a universalidade e para a uniformidade, o saber popular aponta para a especificidade e para a diversidade" (LOPES, 1993, p. 18).

Nesse sentido, Lopes (1993) aponta ainda que não se busca uma igualdade epistemológica entre os saberes populares e científicos, mas a pluralidade dos saberes, considerando-os como possíveis e válidos dentro de seus limites de atuação. No contexto escolar, argumenta a favor de uma inter-relação entre os saberes, de forma a contribuir para a construção do conhecimento escolar sem, contudo, os descaracterizar.

No que se refere à inserção dos saberes populares no Ensino de Ciências, alguns trabalhos analisados buscam debater as propostas curriculares, no tocante ao multiculturalismo e ao cientificismo. Ao tratar dos Parâmetros Curriculares Nacionais (PCN), no que diz respeito ao multiculturalismo, Silva (2002) questiona como seria possível respeitar a diversidade com a determinação de parâmetros, que já trazem, no próprio termo, a ideia de padrões a serem seguidos. Para o autor, as diferenças culturais são abordadas nos PCN sob o ponto de vista da cultura dominante, revelando a importância do respeito à diversidade sem, contudo, levar 
a uma reflexão sobre como essas desigualdades foram constituídas, quais os mecanismos e relações históricas que levaram ao empoderamento de determinadas culturas em detrimento de outras. Assim, as propostas apresentadas nos Parâmetros Curriculares Nacionais não geram uma mudança concreta na sociedade, e as discussões têm "como ponto de chegada uma homogeneidade que apaga todas as construções coletivas das diferentes manifestações culturais fazendo com que continuem naturalizadas as desigualdades" (SILVA, 2002, p. 3).

Em outro trabalho, Silva (2004) apresenta uma crítica aos currículos, que são alicerçados no método científico e no progresso da ciência. Nesse contexto, importa questionar o status de superioridade da ciência e buscar novas possibilidades, nas quais a ciência seja uma dentre outras formas possíveis de se ler o mundo, para que outras alternativas possam habitar o currículo escolar. Não se trata de subordinar o conhecimento científico ao popular, mas de reconhecer os saberes populares como uma dentre outras formas de conhecimento.

Este viés possibilitaria, entre outros fatores, o alargamento da racionalidade, o reconhecimento do pluralismo da ciência, a desnaturalização de concepções que veem a ciência como construção somente de iniciados e também o quanto àqueles ditos iletrados são alfabetizados cientificamente. (SILVA, 2004, p. 8)

Silva $(2002,2004)$ compreende a inserção dos saberes populares na escola como uma possibilidade de construção coletiva do conhecimento a partir da diversidade cultural de diferentes grupos e suas lógicas próprias de leitura do mundo. Para Baptista (2010), é preciso atentar-nos para uma não supervalorização da ciência em detrimento dos saberes culturais dos estudantes.

Apoiada em estudos de William Cobern e Cathleen Loving, Baptista (2010) defende a demarcação e a não anulação dos saberes, ou seja, é importante que o estudante compreenda os conceitos científicos sem, contudo, tê-los como válidos ou verdadeiros em suas vidas. A demarcação dos saberes propicia uma ampliação das concepções dos estudantes, e não a sua substituição. Segundo o construtivismo conceitual, a visão de mundo de um indivíduo é condicionada pelo contexto sociocultural no qual está inserido. Sendo assim, quando o estudante chega à escola, ele já traz consigo uma rede de significados, construídos a partir de suas vivências, o que torna as salas de aula um ambiente heterogêneo, já que reúne estudantes vindos de diferentes contextos sociais. Ensinar ciências deve ser entendido, dentro dessa visão, como o ensino de uma segunda cultura, mas sem que esta entre em choque com a cultura dos estudantes. Assim, os estudantes devem se apropriar da linguagem científica de tal forma que esta faça sentido dentro de seu cotidiano, apresentando significados reais e não servindo somente como conceitos abstratos.

O conceito de pluralismo epistemológico se apoia na ideia de que os estudantes não devem abandonar suas visões de mundo, passando a crer na ciência como única fonte de conhecimentos válidos. Assim, o Ensino de Ciências deve 
permitir aos estudantes o reconhecimento dos

domínios particulares do discurso em que as suas concepções e as ideias científicas tenham - cada qual no seu contexto - alcance e validade. Nesta perspectiva, é preciso criar situações para que os estudantes percebam como a prática da ciência pode se beneficiar dos achados de outros domínios de conhecimento e, do mesmo modo, vejam como algumas das ideias da ciência podem ser alcançadas por outros caminhos epistemológicos. (BAPTISTA, 2010, p. 687)

A demarcação dos saberes só será possível a partir do diálogo no qual os estudantes apontem suas concepções e sejam apresentados a uma segunda cultura: a científica. Dentro dessa visão, o estudante irá se apropriar da linguagem científica, como outra forma de leitura dos fenômenos naturais, ampliando seu universo de conhecimento (BAPTISTA, 2010).

Concordamos com o ponto de vista assumido pelos autores de questionamento dos currículos que, apesar de adotarem uma postura multiculturalista, abandonam a ciência primeva local, sendo construídos a partir da ciência ocidental. Ao se estabelecer uma política de conhecimento oficial, busca-se uma "cultura comum em uma sociedade sabidamente dividida em classes e interesses, uma sociedade essencialmente plural e multicultural" (CHASSOT, 2006, p. 166). Ao encararmos a ciência ocidental como uma das possíveis formas de leitura do mundo, abrimos espaço para outras leituras e para a possibilidade de existência de diferentes vias de explicação da natureza. Acreditamos, portanto, que a inserção de saberes populares no Ensino de Ciências deve contribuir não só para desfazer preconceitos, mas para questionar as desigualdades e os mecanismos que contribuem para sua manutenção.

\section{NOVAS ALTERNATIVAS DIDÁTICAS}

Grande parte dos trabalhos encontrados apresenta propostas de resgate e inserção dos saberes primevos nas salas de aula, buscando um ensino menos asséptico, mais próximo da realidade dos estudantes e questionando a supervalorização do conhecimento científico em detrimento de outros saberes construídos pelas sociedades. Nesses trabalhos, os saberes populares seriam utilizados como ferramentas para o ensino de conceitos que abrangem as áreas de química, física, matemática, geografia, entre outras, com propostas que vão desde as séries iniciais do Ensino Fundamental até a educação superior.

De maneira geral, os trabalhos que se enquadram nessa categoria apontam para o desenvolvimento de sentimentos de solidariedade e respeito ao próximo, valorização dos mais velhos e de culturas consideradas de menor prestígio, rompendo assim com atitudes preconceituosas (GONDIM; MÓL, 2008; PRIGOL; DEL PINO, 2009; RESENDE et al., 2010). Algumas pesquisas mostram que a inserção de saberes populares possibilita o reconhecimento da própria história, gerando um sentimento de pertencimento à comunidade (GONDIM; MÓL, 2008; 
PRIGOL; DEL PINO, 2009). Outros autores apontam para uma melhor compreensão da Natureza da Ciência e do seu caráter incerto e transitório (PINHEIRO; GIORDAN, 2010). Como dificuldade para implementação das propostas, os autores citaram a inércia dos estudantes, acostumados a um modelo baseado na transmissão/recepção de conteúdos

(RESENDE et al, 2010). Também chamam a atenção para o desconhecimento, por parte dos professores, dos saberes científicos envolvidos nos saberes populares, bem como o apego ao livro didático e aos conteúdos determinados nos currículos (PINHEIRO; GIORDAN, 2010; RESENDE et al., 2010). Abaixo são apresentadas algumas das intervenções propostas.

Duas propostas foram desenvolvidas pensando-se as séries iniciais do Ensino Fundamental. A partir da elaboração da etnografia da produção artesanal de tijolos na cidade de São João del-Rei e arredores, Gomes e Pinheiro (2000a) buscaram elucidar os conceitos científicos envolvidos no processo, trazendo-os para a sala de aula por meio do desenvolvimento de materiais didáticos. Em uma segunda proposta, Almeida (2012) levantou práticas culturais comuns na cidade de Abaíra (BA), relativas à fabricação de cachaça, em um projeto que contou com a participação de professores da educação básica e estudantes do Ensino Fundamental e do Médio. Baseada no conceito de circularidade entre as culturas, utilizado para "designar a dinâmica da interação de diferentes padrões e lógicas culturais no espaço escolar" (ALMEIDA, 2012, p. 190), a autora propôs situações educativas que trouxessem para a sala de aula conhecimentos que estão à margem da sociedade, chegando a ser silenciados. Com os estudantes foram realizados experimentos e reproduzidas práticas comuns no processo de fabricação e determinação do teor alcoólico da cachaça.

Almeida (2012) parte da perspectiva da circularidade entre as culturas, baseando-se em Maria de Lourdes Rangel Tura (2002), que estabelece um ir e vir entre culturas, o que pode se dar, por exemplo, entre os saberes populares cuja racionalidade difere da lógica técnico-científica, e os saberes científicos. Assim, a escola deve promover a problematização e a ressignificação dos saberes cotidianos por meio da abordagem de temas ancorados nas práticas sociais, buscando articular os processos cognitivos envolvidos nas diferentes racionalidades.

A partir da investigação, de base etnográfica, da produção caseira de doce de leite, Caldeira e Pinheiro (2010) produziram um material hipermídia que traz a descrição escrita e áudio-visual do processo, problematizando-o para interpretação por meio dos saberes científicos. Também partindo da pesquisa de caráter etnográfico, realizada com mulheres responsáveis pela fabricação de sabão de cinzas em cidades do interior de Minas Gerais, Pinheiro e Giordan (2010) e Pinheiro (2012) desenvolveram um material hipermídia etnográfico no qual os conhecimentos químicos são utilizados para análise dos saberes populares, justificando sua inserção na sala de aula. Os autores ressaltam que, apesar de muitos procedimentos realizados na produção do sabão de cinzas serem reforçados pelos conhecimentos químicos, as produtoras também apontam fatores como "olho gordo" 
como prejudicial na fabricação do sabão, contrastando, portanto, diferentes visões de mundo.

Uma contribuição metodológica importante é trazida por Pinheiro e Giordan (2010), que se inspiraram nos referenciais metodológicos da etnografia, a qual se configura, para os autores, "como um guia para interpretação e reconstituição rigorosa dos saberes observados” (p. 364). Trazendo diversos pesquisadores para a discussão, os autores destacam a necessidade de se lançar dois olhares de investigação: o primeiro, aquele que vê o outro a partir da sua ciência, com suas ferramentas próprias, e um outro olhar que coloca de lado os seus instrumentos e procura compreender as práticas por um ângulo interno. Assim, o pesquisador deve estabelecer uma relação simétrica com os seus informantes, permitindo que eles falem segundo a sua lógica própria, sem a imposição de ideias pré-concebidas ou hipóteses formuladas previamente, pois estas raramente refletirão a realidade do grupo investigado.

Gondim e Mól (2008a, 2008b) construíram um material paradidático destinado, principalmente, a professores de Química. O material foi desenvolvido a partir dos saberes de tecelãs do Triângulo Mineiro sobre a tecelagem manual em tear de quatro pedais, os quais foram usados como Tema Gerador, como proposto por Paulo Freire, aliado a uma educação como prática de liberdade. A educação para liberdade parte do diálogo entre educador e educando e da sua inserção na comunidade visando conhecer a sua realidade, suas contradições e demandas. Essas situações precisam ser expostas à comunidade para reflexão e compreensão, o que faz com que o indivíduo perceba sua realidade, a ressignificando. Após esse momento são selecionados os possíveis temas que, em seguida, são reduzidos às áreas de conhecimento, definindo-se as unidades de aprendizagem (FREIRE, 2000). Esse tipo de abordagem reforça a necessidade de se estudar um saber popular próprio do local, e não de outras regiões, pois o reconhecimento da própria realidade permite ao indivíduo se identificar e atuar sobre aquela prática.

Partindo dessas proposições, os autores desenvolveram um material paradidático, descrito a seguir, o qual pode servir como orientação para o desenvolvimento de propostas semelhantes. O material inicia-se com uma apresentação destinada ao professor e uma descrição da tradição da tecelagem manual, situando-a na cultura popular. Em seguida é feita uma apresentação das artesãs, preservando-se os nomes e o modo de falar, a fim de valorizá-las e reconhecê-las como parte integrante de uma cultura. Logo após são apresentadas as etapas envolvidas na tecelagem, com algumas explicações em termos científicos e comparações com a forma industrial de produção, com inserções das falas das artesãs que enfatizam o assunto em questão. A partir daí são sugeridos os saberes científicos e os temas que podem ser abordados a partir das questões levantadas. Em seguida, os autores trazem alguns conteúdos químicos, atividades e estratégias de ensino baseadas na perspectiva CTS - Ciência, Tecnologia e Sociedade - ou na experimentação (GONDIM; MÓL, 2008a). 
Três trabalhos foram propostos a partir dos saberes relacionados à produção artesanal de queijo (PRIGOL; DEL PINO, 2008; PRIGOL; DEL PINO, 2009; PRIGOL; VENQUIARUTO, 2006). Prigol e Vequiaruto (2006) buscaram elucidar alguns conceitos químicos envolvidos no processo de obtenção do coalho a partir da enzima digestiva, a renina, extraída do estômago dos mamíferos. Prigol e Del Pino $(2008,2009)$ trabalharam com estudantes do segundo ano do Ensino Médio de uma escola pública do município de Erechim (RS). A escola tem a particularidade de receber somente meninos, em sua maioria filhos de produtores rurais, em regime de internato, e tem em sua grade curricular uma disciplina sobre produção de queijos.

Prigol e Del Pino (2008) elaboraram uma oficina a partir de aspectos apontados em entrevistas realizadas com produtoras de queijo e em questionários aplicados aos alunos. Os autores desenvolveram na oficina aspectos sociais, tecnológicos e científicos relacionados à produção de queijo. Dentre os aspectos sociais apontados estão questões de gênero, relacionadas à importância do estudo para a mulher e à produção de queijos pelos meninos, visto que essa é uma prática essencialmente feminina na região. Dentre os aspectos tecnológicos e científicos abordados, os autores destacaram algumas etapas da produção de queijos, levantando conceitos relativos a $\mathrm{pH}$, acidez e utilização do coalho.

Prigol e Del Pino (2009) procuraram observar como esses saberes estão relacionados às vivências de estudantes do município de Erechim (RS). Na pesquisa realizada, os autores observaram que a fabricação de queijos fazia parte do cotidiano dos alunos, constituindo a identidade social e cultural do grupo. Em alguns casos, os autores observaram uma valorização dos saberes científicos em detrimento dos populares. Outros estudantes reconheceram que os saberes científicos, aprendidos na escola, podem contribuir para melhorar a prática de fabrico de queijo, gerando mudanças na forma como é realizado por suas famílias.

Atividades experimentais foram propostas por Venquiaruto et al. (2011a, 2011b, 2013b, 2013c) e Venquiaruto, Dallago e Del Pino (2012), a partir da produção artesanal de pão, vinho e cachaça, enfatizando conteúdos químicos. Venquiaruto et al. (2010, 2013a) e Santos et al. (2012) também propuseram a realização de experimentos a partir da investigação do uso de cinzas nos afazeres domésticos, para limpeza de utensílios, com o objetivo principal de verificar a viabilidade da substituição da soda cáustica pelo extrato aquoso de cinzas na produção artesanal de sabão.

Outra possibilidade de inserção de saberes populares no contexto escolar foi apresentada por Resende et al. (2010), que investigaram a produção artesanal de vinho de laranja e apresentaram uma sequência de aulas, desenvolvidas com estudantes da terceira série do Ensino Médio, nas quais a temática foi debatida. Os autores destacam que, na inserção de saberes populares no currículo, deve-se observar a diferença entre a linguagem utilizada pelos produtores e a linguagem explicativa da ciência. Um exercício importante seria compará-las explorando as aplicações e as validades de cada uma, observando os diferentes modos com que 
os conhecimentos populares e os conhecimentos científicos são construídos.

Siqueira e Chassot (2004) propuseram intervenções em turmas de estudantes trabalhadores da Educação de Jovens e Adultos - EJA. Os autores relataram o quanto os estudantes se sentiram valorizados ao exporem seus conhecimentos para a turma, colaborando para o aumento da autoestima.

Gomes e Pinheiro (2000) trouxeram uma proposta para cursos de Engenharia. Os autores descrevem o processo artesanal de fabrico de tijolos, desde a etapa de escolha de um terreno mais propício à realização da atividade até o processo de queima dos tijolos. Assim, por meio de uma pesquisa etnográfica sobre o processo de produção artesanal de tijolos, os autores pretendem gerar reflexões pedagógicas que alcancem os cursos de Engenharia.

A elaboração e aplicação de propostas como as descritas acima passa, primeiramente, pela iniciativa do professor. Precisamos de um professor que não se preocupe somente com os conteúdos, mas também com a formação de cidadãos capazes de efetuar leituras do mundo e se disponham a transformá-lo para melhor. Do total de publicações levantadas, seis procuram gerar reflexões sobre a inserção de saberes populares na prática docente.

Chassot relata atividades de busca de saberes populares desenvolvida com alunos do curso de Pedagogia. Chassot (2004) apresentou duas concepções sobre a ciência e a ética. A primeira delas, a idealista, é caracterizada pela aceitação de normas universais e eternas, que determinam o modo como a ciência deve se desenvolver. A outra, a visão histórica, entende a ciência e a ética como uma construção e, portanto, não sujeitas a leis eternas, o que nos possibilita pensar em novas perspectivas para o futuro. Embasada nessas concepções, a atividade desenvolvida por Chassot $(2004,2007,2008$ a) consistia na realização de entrevistas com pessoas de mais de 75 anos, perguntando por conhecimentos presentes na vida do entrevistado há 50 ou 60 anos. O autor destaca a possibilidade de um ensino menos asséptico, matematizado e descontextualizado, no qual o saber científico não vem para ratificar e, assim, validar o saber popular, mas se torna um facilitador da leitura do mundo natural. Destaca, ainda, o diálogo entre as gerações, a oposição ao cientificismo e ao presenteísmo e a valorização dos mais velhos e não letrados como fontes de conhecimento.

Pensando a formação de professores, Menegat e Venquiaruto (2006) e Venquiaruto et al. (2009) propuseram a licenciandos dos cursos de Química e Biologia atividades relacionadas à produção artesanal de geleias e à salga da carne, respectivamente. As atividades permitiram aos estudantes relacionar um saber popular a um conhecimento formal, bem como questionar os saberes valorizados pela escola básica.

Como já descrito anteriormente, Almeida (2012) desenvolveu um trabalho com estudantes dos ensinos Fundamental e Médio e com professores da educação básica. Em uma das etapas da pesquisa foram realizados encontros com os professores para tratarem do uso do ajofe e do alcoômetro na produção de cachaça, observando os conceitos científicos que justificam seu uso. O uso do ajofe, 
instrumento tradicional utilizado para determinação do teor alcoólico da cachaça, tem sido questionado e substituído pelo alcoômetro, o qual envolve o emprego da racionalidade técnico-científica. Para Almeida (2012), ao final do processo, professores e alunos passaram a atribuir novos valores à prática local de produção de cachaça, lançando um novo olhar sobre as situações cotidianas. Nos professores houve, ainda, modificações na própria concepção de aprendizagem, que passou a ser vista sob o ponto de vista da ancoragem social dos conteúdos.

Acreditamos que propostas como as descritas acima, que possibilitam a inserção de saberes populares no Ensino de Ciências, são válidas na medida em que os conhecimentos populares são valorizados e inseridos no diálogo entre os conhecimentos científicos e escolares. Entretanto, é preciso cuidado para que os saberes populares não sirvam só como uma ferramenta de ensino, como exemplificação de conceitos, sem a exploração de outros aspectos que contribuem para uma formação mais humana do estudante.

Compondo uma interlocução interessante com a categoria acima apresentada, Canclini (1998, p. 173), ao discutir as formas como o Estado mexicano expõe o seu patrimônio cultural em museus, e também sobre livros que tratam de artesanatos, festas, poesias e músicas tradicionais, argumenta que "os objetos antigos são separados das relações sociais para os quais foram produzidos”, ou seja, os objetos são transformados em obras destituídas de propósito e função original para os quais foram criados. São também apresentados de tal forma que aparentam uma uniformidade e pureza, escondendo "as contradições sociais presentes no nascimento dessas obras” (CANCLINI, 1998, p. 175), ocultando os conflitos e os processos históricos que marcaram sua constituição.

Essa preocupação é válida também quando nos apropriamos dos saberes populares no ambiente escolar. Assim, ao inserirmos os saberes populares na sala de aula, é preciso cuidado para que eles não se tornem “obras de museu” a serem observadas, esvaziadas de seu significado real. Buscar compreender, portanto, o meio de onde emergem esses conhecimentos, sua função original e as contradições que eles carregam deve ser uma etapa fundamental na inserção de saberes populares na sala de aula.

\section{TROCA DE CONHECIMENTOS COM A COMUNIDADE}

Observamos que um pequeno grupo de pesquisadores se preocupou em não só resgatar os saberes populares, mas estudá-los e propor alternativas para melhoria da qualidade dos produtos artesanais. Assim, embora alguns trabalhos proponham conteúdos curriculares a partir do conhecimento popular estudado, entendemos que o foco das pesquisas estava em fornecer um retorno à comunidade.

Silva et al. (2000) exploraram o processo de fabricação de medicamentos fitoterápicos desenvolvidos pelo CEMPO - Centro de Educação e Medicina Popular, localizado na comunidade do Córrego do Jenipapo, em Recife (PE). Embasados na perspectiva da pesquisa-ação e em estudos realizados na área de 
produção de medicamentos fitoterápicos, os autores levantaram alguns aspectos que poderiam comprometer a qualidade dos produtos e propuseram pequenas alterações no processo de fabricação.

Também pesquisando sobre o uso de plantas medicinais, Stockmann et al. (2007) realizaram um levantamento das espécies medicinais conhecidas pelos moradores da cidade de Luminárias (MG), bem como seu uso, buscando entender como esse conhecimento vem sendo mantido ao longo de gerações. O retorno dos conhecimentos levantados para a comunidade foi feito a partir de uma palestra e a elaboração de uma cartilha sobre plantas medicinais nativas e cultivadas, nas quais foram apresentadas as espécies mais comuns na região e aquelas que podem ser cultivadas com facilidade nos quintais.

Após investigar o processo de melhoramento genético realizado por agricultores, que não possuem formação acadêmica, em sementes de milho da espécie crioulo, Campos (2007) buscou demonstrar como o cultivo dessa espécie se insere de forma econômica e cultural nas comunidades do oeste catarinense. $\mathrm{O}$ autor defendeu, ainda, a possibilidade de um novo olhar sobre a prática dos agricultores, que, por dominarem a tecnologia e o conhecimento necessários ao processo de melhoramento genético, produzem trabalho intelectual. Partindo de uma perspectiva ainda não encontrada nos trabalhos levantados, o autor apresenta uma proposta de interação entre os campos educacional e jurídico, defendendo a posse da propriedade intelectual de melhoramento das sementes para os agricultores, impedindo o patenteamento por empresas de biotecnologia.

Visando alcançar um retorno para as práticas e comunidades estudadas, Silva et al. (2000) trazem como contribuição metodológica os referenciais da pesquisa-ação, especificamente de Thiollent (1994), a qual objetiva a resolução de situações problemáticas trazendo encaminhamentos para uma tomada de consciência e/ou uma produção coletiva de conhecimentos. Entendemos que a interação entre o pesquisador e a comunidade pesquisada deve ir além da simples busca de seus conhecimentos. Como argumenta Chassot (2006), o retorno à comunidade é uma necessidade social, é torná-la mais do que espaço de pesquisa, é valorizá-la. O oferecimento de novas alternativas não significa mudar as práticas locais, mas responder às necessidades que a própria comunidade possui. Entretanto, cabe questionar até que ponto é válida essa preocupação. Será que esse retorno é uma necessidade da comunidade ou será que esse é um argumento que parte de uma perspectiva que nos coloca, enquanto pesquisadores, detentores de um conhecimento validado em uma posição de superioridade. É preciso observar, portanto, se essa é uma real necessidade do grupo investigado, ou um desejo que parte dos pesquisadores, e respeitar essa necessidade ou a ausência dela.

\section{INVESTIGANDO AS TRANSFORMACִÕES OCORRIDAS AO LONGO DO TEMPO}

Do total de trabalhos levantados, cinco tratam das transformações pelas quais determinados saberes populares passaram ao longo do tempo. Embora apre- 
sentem reflexões sobre o papel da escola diante dessas modificações, bem como alguns apontamentos para o Ensino de Ciências, esses trabalhos se dedicam a entender as influências do contexto histórico e social sobre o conhecimento popular, mostrando assim que a cultura não é estática.

Reichert (2000) investigou, por meio de entrevistas, a história das famílias de seus alunos, a maioria migrantes rurais que abandonaram o trabalho na roça, vítimas da modernização da agricultura. Foram levantadas as diferenças entre a vida no campo e a vida na cidade, bem como as formas de vida modificadas pelo êxodo rural. Assim, os estudantes reconheceram o processo histórico vivenciado pelas suas famílias, preservando suas próprias raízes. Nesse sentido, "O trabalho de preservar os saberes e a história das famílias pretendeu fazer da valorização da cultura rural uma forma de religar-se a suas origens estando em outro lugar" (REICHER'T, 2000, p. 10).

Ao falar sobre o presenteísmo, marca dos nossos dias, Chassot (2006) argumenta que o resgate do passado contribui para suprir a falta de amarras que, geralmente, nossos alunos têm com as suas raízes, obtendo lições para construir o futuro. Para Warnier (2003), a cultura e a língua de um povo são sua identidade e, à medida que nos são transmitidas e incorporadas, passam a constituir nosso pensamento, nos identificando como determinado povo e guiando nossas ações.

Ao buscar um Ensino de Ciências que favoreça a formação de cidadãos, Gondim e Mól (2009) apresentaram uma discussão acerca das relações CTS a partir dos saberes populares referentes à tecelagem manual em tear de quatro pedais. Os autores apresentam recortes das entrevistas realizadas com artesãs de cidades do Triângulo Mineiro, apontando para a relação da ciência e da tecnologia com a história da sociedade e sua cultura em diferentes épocas. Gondim e Mól (2009) observaram como as mudanças científicas e tecnológicas alteraram os fazeres das artesãs. Os autores relacionaram as mudanças ocorridas na prática das artesãs com aspectos históricos, como a Revolução Industrial, e a história da ciência, mostrando como a sociedade pode ter o controle sobre a ciência e a tecnologia, e quais as implicações sociais de seu desenvolvimento.

Almeida (2008, 2011) e Mendes e Almeida (2011) teceram reflexões a partir dos saberes relativos à produção de cachaça na região de Abaíra-BA, no que diz respeito à implementação de exigências de padrões de qualidade e fiscalização de órgãos governamentais.

Almeida (2008) acompanhou durante cinco meses as ações de um produtor diante da necessidade de escolha entre produzir a cachaça comum ou produzir a cachaça de qualidade. A autora descreve todo o processo de produção dos dois tipos de cachaça, mostrando os deslocamentos entre a maneira como era produzida por seus antepassados e os métodos utilizados para a produção de uma cachaça de qualidade, certificada pelos órgãos competentes. Almeida mostra como o estereótipo de resistência à mudança, atribuído aos produtores de cachaça, não se aplica a todos os casos, visto que muitas inovações tecnológicas são apropriadas pelos produtores que ressignificam o conhecimento tradicional, adequando-o a 
uma nova realidade. Para a autora, os produtores transitam entre modos diferentes de pensamento, ora apresentam uma incorporação do conhecimento científico, ora suspendem esse discurso e trazem os conhecimentos tradicionais, não representando, assim, uma ruptura entre esses saberes.

Por outro lado, muitos produtores enfrentam dificuldades para implementação de exigências de padrões de qualidade da cachaça, com a incorporação de inovações tecnológicas ao processo artesanal, como tratado por Mendes e Almeida (2011). As ações de regularização das unidades de produção e aplicação da legislação pertinente, desenvolvidas pelo Ministério da Agricultura, Pecuária e Abastecimento, geraram um clima de tensão entre os produtores e debates no município. Nesse contexto, os autores questionam se "as escolas não poderiam, através da problematização do contexto sociocultural, contribuir para a produção de um discurso sensível à pluralidade de realidades" (MENDES; ALMEIDA, 2011, p. 7). Assim, o espaço escolar se configuraria como um lugar favorável à problematização das tensões sociais, favorecendo atitudes conscientes no cotidiano.

Em outro trabalho, Almeida (2011) se dedicou a entender a modificação dos padrões de higiene ao longo do tempo e como essas práticas são incorporadas pelos produtores. Embora eles conheçam as recomendações técnicas, a higiene e o cuidado com a produção variam de acordo com o tipo de cachaça produzida, sendo observada na produção da cachaça de qualidade, que é vendida a um preço maior e desconsiderada na produção da cachaça comum. Muitos produtores compreendem a destilação da cachaça como um processo de limpeza que, por si só, garante a higienização do produto final. Nesse contexto de descompasso entre a legislação vigente, no que tange aspectos básicos de higiene, e o praticado pelos produtores, Almeida aponta como papel da escola não só a valorização da cultura local, mas também mostrar "que ela não é fixa e que a sua transformação pode contribuir para atenuar as desigualdades, desde que sejam respeitados certos aspectos essenciais que garantem o reconhecimento pessoal e social" (ALMEIDA, 2011, p. 10).

Ao investigarmos como os saberes populares se modificam com o passar do tempo e quais os fatores que influenciam essa mudança, podemos observar como a sociedade se relaciona com a ciência e a tecnologia, quais as influências de uma sobre a outra e como diferentes culturas - urbana, popular, científica, entre outras - se movem e se interpenetram. Assim, como argumentam Pinheiro e Giordan (2010), mais do que conservar as tradições, é necessário entender como ocorrem essas interações e as modificações que elas provocam. Mais importante, portanto, que conservar inalteradas as formas é entender como ocorre sua reelaboração para atender às necessidades presentes.

$\mathrm{Na}$ categoria acima apresentada, os autores trazem alguns apontamentos que nos permitem pensar o papel da escola diante da tradição e da dualidade tradição/modernidade, destacando o espaço educativo como um local propício à problematização das tensões da vida comunitária, o que requer a realização de estudos da comunidade, conhecendo-se as especificidades e práticas locais e o universo 
cultural dos estudantes. Dessa forma, desloca-se o foco de conteúdos universais para a busca de sentido ao fazer cotidiano.

\section{CONSIDERACִÕES FINAIS}

Apresentamos nesse estudo um olhar para trabalhos que abordam o tema saberes populares na educação científica. Embora nem todos os trabalhos já realizados tenham sido levantados, conseguimos obter um panorama geral das pesquisas sobre o tema na área de Ensino de Ciências. O fato de levantarmos, inicialmente, somente oito artigos na busca em seis periódicos por um período de doze anos, nos mostra que os estudos sobre saberes populares e sua publicação encontram-se ainda em desenvolvimento, apontando para a necessidade de mais pesquisas.

Os temas desenvolvidos nos estudos encontrados concentram-se, principalmente, na proposta de novas alternativas didáticas para a Educação Básica, nas quais os saberes populares são utilizados como ponto de partida para a realização de atividades. Entretanto, observamos poucas pesquisas voltadas para a formação inicial de professores, o que acreditamos ser uma etapa fundamental para que mais propostas semelhantes sejam implementadas na educação básica.

Os saberes populares em si também foram objeto de investigação dos trabalhos encontrados, tanto no que diz respeito às mudanças que determinados saberes sofreram ao longo do tempo quanto no que diz respeito às trocas de conhecimentos entre a comunidade e os pesquisadores, a partir da pesquisa com o tema. Tais estudos mostram que problematizar o contexto sociocultural de onde emergem esses conhecimentos, entender de que forma o tradicional e o moderno se relacionam e como um pode se beneficiar com os achados do outro são caminhos que podem contribuir para atenuar desigualdades sociais. Observar como os saberes populares se modificam ao longo do tempo nos permite compreender como os aspectos da modernidade, a ciência e a tecnologia se relacionam com as culturas tradicionais, como estas são transformadas para se adequarem às necessidades atuais.

Foram encontrados também estudos que têm como objeto reflexões teóricas a respeito dos saberes populares e que colocam o foco das discussões em questões curriculares, propondo a distinção entre saberes populares e senso comum e a adoção do multiculturalismo como prática curricular, por exemplo.

A partir dos trabalhos encontrados é possível perceber que a pesquisa sobre saberes populares na área de Ensino de Ciências, apesar de ainda incipiente, se desenvolve sobre eixos educacionais importantes, abarcando estudos que problematizam currículos, práticas pedagógicas e questões epistemológicas relativas ao tema. Pela concentração de trabalhos em temas relativos a questões de prática e utilização em sala de aula, percebemos a necessidade de ampliação da discussão em torno de questões epistemológicas, discutindo a hierarquização de saberes posta pela ciência, que apaga e destitui de sentidos para os estudantes conhecimentos oriundos de suas comunidades e famílias. Estudos a respeito da inserção 
do trabalho com saberes populares no currículo de ciências também precisam ser desenvolvidos, pois as questões curriculares influenciam diretamente no (não) aparecimento desses temas em salas de aula de ciências.

Acreditamos, contudo, que precisa haver um diálogo maior entre as reflexões teóricas apresentadas e as propostas efetivadas, de forma que estas resultem em um questionamento maior das desigualdades e do status de superioridade do conhecimento científico. A interlocução dos saberes populares com o Ensino de Ciências deve, nesse sentido, partir de um saber local, das suas contradições e demandas, permitindo um ensino dentro de um contexto real, contribuindo para a formação de um indivíduo mais crítico e capaz de atuar na construção de uma sociedade menos desigual.

\section{REFERÊNCIAS}

ALMEIDA, R. O. Cultura e inovação tenológica: a compra da moenda. In: Encontro de Estudos Multidisciplinares em Cultura, 4., 2008, Salvador. Anais... Salvador, 2008.

ALMEIDA, R. O. Limiares de tolerância à sujeira, destilação e o ensino de ciências: uma perspectiva histórico-cultural. In: Encontro Nacional de Pesquisa em Educação em Ciências, 8., 2011, Campinas. Anais... Campinas, 2011.

ALMEIDA, R. O. Ajofe e alcoometria: as escolas diante das mudanças socioculturais ligadas à produção de cachaça artesanal na microrregião de Abaíra, Bahia, Brasil. Ciência \& Educação, Bauru, v. 18, n. 1, p. 187-214, jan/abr. 2012.

AYALA, M.; AYALA, M. I. N. Cultura popular no Brasil: perspectiva de análise. São Paulo: Ática, 1987.

BAPTISTA, G. C. S. Importância da demarcação de saberes no ensino de ciências para as sociedades tradicionais. Ciência \& Educação, Bauru, v.16, n. 3, p. 679-694, set/dez. 2010.

CALDEIRA, S. A.; PINHEIRO, P. C. Os saberes químicos presentes na produção popular de doce de leite e a sua mediação para a sala de aula utilizando um sistema hipermídia. In: Encontro Nacional de Ensino de Química, 15., 2010, Brasília. Anais... Brasília, 2010.

CAMPOS, A. V. Sementes de vida: pesquisa e propriedade intelectual. In: Congresso Internacional de Educação, 5., 2007, São Leopoldo. Anais... São Leopoldo, 2007.

CANCLINI, N. G. Culturas híbridas: Estratégias para entrar e sair da modernidade. 2. ed. São Paulo: Editora da Universidade de São Paulo, 1998.

CHASSOT, A. Saberes Populares fazendo-se saberes escolares: uma alternativa para a alfabetização científica. In: Seminário de Pesquisa em Educação da Região Sul, 5., 2004, Curitiba. Anais... Curitiba, 2004.

CHASSOT, A. Alfabetização cientifica: questões e desafios para a educação. 4. ed. Ijuí: Unijuí, 2006. 
CHASSOT, A. Haciendo educación en ciencias en los estudios de Pedagogía con la inclusión de saberes populares en el currículum. Alambique. Didáctica de las Ciencias Experimentales, n. 51, p. 20-25, 2007.

CHASSOT, A. Fazendo Educação em Ciências em um Curso de Pedagogia com Inclusão de Saberes Populares no Currículo. Química Nova na Escola, São Paulo, n. 27, p. 9-12, fev. 2008a.

CHASSOT, A. Sete escritos sobre educação e ciência. 1.ed. São Paulo: Cortez, 2008b. FREIRE, P. Pedagogia do oprimido. 28. ed. Rio de Janeiro: Paz e Terra, 2000.

GOMES, A. S.; PINHEIRO, P. C. A produção artesanal de tijolos: um saber patrimonial estudado nas aulas de ciências de uma sala multisseriada. In: Reunião Anual da Sociedade Brasileira de Química, 23., 2000a, Poços de Caldas. Anais... Poços de Caldas, 2000a.

GOMES, A. S.; PINHEIRO, P.C. O resgate dos saberes envolvidos na engenharia popular de fabrico de tijolos. In: Congresso Brasileiro de Ensino de Engenharia, 28., 2000b, Ouro Preto. Anais... Ouro Preto, 2000b.

GONDIM, M. S. C. A inter-relação entre saberes cientificos e saberes populares na escola: uma proposta interdisciplinar baseada em saberes das artesãs do Triângulo Mineiro. 2007. 174 f. Dissertação (Mestrado Profissionalizante em Ensino de Ciências) - Programa de Pós-Graduação em Ensino de Ciências, Universidade de Brasília, Brasília, 2007.

GONDIM, M. S. C.; MÓL, G.S. Interlocução entre os saberes: relações entre os saberes populares de artesãs do triângulo mineiro e o ensino de ciências. In: Encontro Nacional de Pesquisa em Educação em Ciências, 7., 2009, Florianópolis. Anais... Florianópolis, 2009.

GONDIM, M. S. C.; MÓL, G. S. Saberes Populares e Ensino de Ciências: Possibilidades para um trabalho interdisciplinar. Química Nova na Escola, São Paulo, n. 30, p. 3-9, nov. 2008a.

GONDIM, M. S. C.; MÓL, G. S. Saber Popular e ensino de ciências: possibilidades para um trabalho interdisciplinar. In: Encontro Nacional de Ensino de Química, 14., 2008b, Curitiba. Anais... Curitiba, 2008b.

LOPES, A. R. C. Reflexões sobre currículo: as relações entre senso comum, saber popular e saber escolar. Em Aberto, Brasília, n. 58, p. 14-23, abr/jun. 1993.

LOPES, A. R. C. Conbecimento escolar: ciência e cotidiano. Rio de Janeiro: EdUERJ, 1999.

MENDES, B. A.; ALMEIDA, R. O. “Querem fechar os engenhos antigos!”: Possibilidades de abordagem escolar dos dilemas entre Cultura Cotidiana e Cultura técnico-científica. In: Encontro de Estudos Multidisciplinares em Cultura , 7., 2011, Salvador. Anais... Salvador, 2011.

MENEGAT, G. C.; VENQUIARUTO, L.D. A aprendizagem através dos saberes populares. In: Reunião Anual da Sociedade Brasileira de Química, 29., 2006, Águas de Lindoia. Anais... Águas de Lindoia, 2006. 
PINHEIRO, P. C. A interação de uma sala de aula de química de nível médio com o Hipermidia Etnográfico sobre o sabão de cinzas vista através de uma abordagem sócio (trans)cultural de pesquisa. 2007. 859 p. Tese (Doutorado em Educação) - Faculdade de Educação, Universidade de São Paulo, São Paulo, 2007.

PINHEIRO, P. C. Estabelecendo "pontes" entre a cultura popular, a cultura dos alunos e a ciência escolar a partir de um instrumento hipermídia etnográfico. Disponível em: < http://www.lapeq.fe.usp.br/pesquisas/pdf/resumo_expandido_paulo.pdf $>$. Acesso em: 15 jul. 2012.

PINHEIRO, P. C.; GIORDAN, M. O preparo de sabão de cinzas em Minas Gerais, Brasil: do status de etnociência à sua mediação para a sala de aula utilizando um sistema hipermídia etnográfico. Investigações em Ensino de Ciências, Porto Alegre, v. 15, n. 2, p. 355-383, ago. 2010.

PRIGOL, S.; DEL PINO, J. C. O saber popular como uma alternativa temática para a estruturação curricular do ensino de ciências. In: Encontro Nacional de Ensino de Química, 14., 2008, Curitiba. Anais... Curitiba, 2008.

PRIGOL, S.; DEL PINO, J. C. Concepção e envolvimento de alunos do ensino médio de uma escola pública do município de Erechim/RS sobre a relação: saber popular do queijo x saber científico no currículo de ciências. Revista de Educação do IDEAU, v. 4, n. 8, jan/jun. 2009.

PRIGOL, S.; VENQUIARUTO, L. D. Valorização de saberes populares relacionados com a produção de queijo. In: Reunião Anual da Sociedade Brasileira de Química, 29., 2006, Águas de Lindoia. Anais... Águas de Lindoia, 2006.

REICHERT, I. C. Buscando criar raízes: preservação dos saberes de famílias de migrantes rurais em uma prática de Educação Ambiental. Revista de Estudos (Novo Hamburgo), Novo Hamburgo, v. 23, p. 47-58, jul/dez. 2000.

RESENDE, D. R.; CASTRO, R. A.; PINHEIRO, P. C. O Saber popular nas aulas de química: Relato de experiência envolvendo a produção do vinho de laranja e sua interpretação no ensino médio. Química Nova na Escola, São Paulo, v. 32, n. 3, p. 151-160, ago. 2010.

SANTOS, D. et al. Produção de Sabão utilizando extrato aquoso de cinzas. In: Encontro de Química da Região Sul, 19., 2012, Tubarão. Anais... Tubarão, 2012.

SILVA, D. Contradições do currículo oficial: uma abordagem multicultural. In: Encontro Nacional de Educação Social, 2., 2002, Maringá. Anais... Maringá, 2002.

SILVA, D. Saber Popular fazendo-se saber escolar. In: Seminário de Pesquisa em Educação da Região Sul, 5., 2004, Curitiba. Anais... Curtitiba, 2004.

SILVA, P. B.; AGUIAR, L. H.; MEDEIROS, C. F. O papel do professor na produção de medicamentos fitoterápicos. Química Nova na Escola, São Paulo, n. 11, p.19-23, mai. 2000.

SIQUEIRA, A. B.; CHASSOT, A. Etnobotânica no currículo de ciências do ensino fundamental na educação de jovens e adultos - EJA. In: Seminário 
de Pesquisa em Educação da Região Sul, 5., 2004, Curitiba. Anais... Curitiba, 2004.

STOCKMANN, R. et al. Percepção e resgate dos saberes populares de Luminárias/MG. Revista Brasileira de Agroecologia, Cruz Alta, v. 2, n. 1, fev. 2007.

VENQUIARUTO, L.; DALLAGO, R.; DACROCE, C. F. Saberes populares relacionados com a salga da carne fazendo-se saberes escolares. In: Reunião Anual da Sociedade Brasileira de Química, 32., 2009, Fortaleza. Anais... Fortaleza, 2009.

THIOLlent, M. Metodologia da pesquisa-ação. São Paulo: Ed. Cortez, 1994.

TURA, M. de L. R. Conhecimentos escolares e a circularidade entre culturas. In: LOPES, A. C.; MACEDO, E. (Org.). Currículo: debates contemporâneos. São Paulo: Cortez, 2002. p.150-173.

VENQUIARUTO, L. D. et al. Avaliação do emprego do extrato aquoso de cinzas na produção artesanal de sabão. In: Encontro de Debates sobre o Ensino de Química, 33., 2013, Ijuí. Anais... Ijuí, 2013a.

VENQUIARUTO, L. D.; DALLAGO, R. M.; DEL PINO, J. C. Saberes populares fazendo-se saberes escolares: um estudo envolvendo a produção artesanal do vinho. In: Encontro de Química da Região Sul, 19., 2012, Tubarão. Anais... Tubarão, 2012.

VENQUIARUTO, L. D. et al. Saberes populares fazendo-se saberes escolares: um estudo envolvendo a produção artesanal do vinho. In: Encontro de Debates sobre o Ensino de Química, 33., 2013, Ijuí. Anais... Ijuí, 2013b.

VENQUIARUTO, L. D. et al. Saberes populares fazendo-se saberes escolares: um estudo sobre a cachaça artesanal. In: Encontro de Debates sobre o Ensino de Química, 33., 2013, Ijuí. Anais... Ijuí, 2013c.

VENQUIARUTO, L. D. et al. Saberes Populares Fazendo-se Saberes Escolares: Um estudo envolvendo a produção artesanal do pão. Química Nova na Escola, São Paulo, v. 33, n. 3, p. 135-141, ago. 2011a.

VENQUIARUTO, L. D. et al. Saberes populares fazendo-se saberes escolares: um estudo envolvendo a produção artesanal do pão. In: Reunião anual da Sociedade Brasileira de Química, 34., 2011b, Florianópolis. Anais... Florianópolis, 2011b.

VENQUIARUTO, L. D. et al. Saberes populares fazendo-se saberes escolares: um estudo envolvendo extrato aquoso de cinzas. Perspectiva, Erechim, v. 34, n. 127, p. 91-98, set. 2010.

WARNIER, J. A mundialização da cultura. 2. ed. Bauru: EDUSC, 2003.

Data de recebimento: $13 / 01 / 2014$

Data de aprovação: 16/05/2015

\section{Contato autor:}

Patrícia Maria Azevedo Xavier

Universidade Federal de Juiz de Fora, Faculdade de Educação, Rua José Lourenço Kelmer, s/n Campus Universitário - São Pedro, CEP 36036-330, Juiz de Fora - MG

E-mail: pma.xavier@yahoo.com.br 